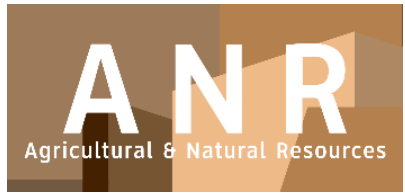

PAPER - OPEN ACCESS

\title{
Tahanan Penetrasi Tanah Terhadap Penekanan Plat Dengan Sudut Penekanan dan Ukuran Plat yang Berbeda di Sawah
}

\author{
Author : Taufik Rizaldi \\ DOI : : 10.32734/anr.v1i2.244 \\ Electronic ISSN : :2654-7023 \\ Print ISSN : 2654-7015
}

Volume 1 Issue 2 - 2018 TALENTA Conference Series: Agricultural \& Natural Resources (ANR)

\section{(2) $(1)$}

This work is licensed under a Creative Commons Attribution-NoDerivatives 4.0 International License.

Published under licence by TALENTA Publisher, Universitas Sumatera Utara
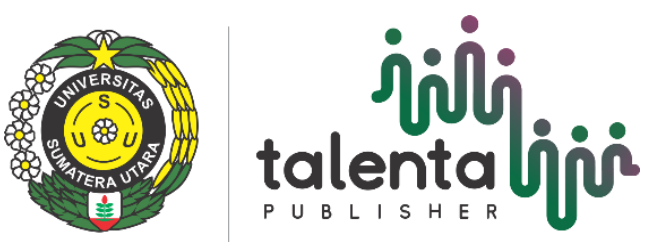


\title{
iji \\ ANR Conference Series 01 (2018), Page 238-243 \\ TALENTA Conference Series \\ Available online at https://talentaconfseries.usu.ac.id
}

\section{Tahanan Penetrasi Tanah Terhadap Penekanan Plat Dengan Sudut Penekanan dan Ukuran Plat yang Berbeda di Sawah}

\author{
Taufik Rizaldi ${ }^{\text {a*}, \text { Sumono }^{\mathrm{a}}}$ \\ ${ }^{a}$ Fakultas Pertanian, Universitas Sumatera Utara, Medan, Indonesia \\ taufik.rizaldi@usu.ac.id
}

\begin{abstract}
Abstrak
Penelitian dilakukan di Desa Lubuk Bayas Kecapamatan Perbaungan Kabupaten Serdang Bedagai pada lahan sawah bertekstur lempung berpasir dengan kadar air $49.17 \%$ dan dry bulk density $1.26 \mathrm{~g} / \mathrm{cm}^{3}$. Tahanan penetrasi tanah ditentukan melalui pengukuran tahanan penetrasi plat dengan menggunakan penetrometer secara langsung di sawah. Pengukuran dilakukan dengan ukuran plat $5 \times 5 \mathrm{~cm}^{2}, 5 \times 10 \mathrm{~cm}^{2}, 5 \times 15 \mathrm{~cm}^{2}$ dan $5 \times 20 \mathrm{~cm}^{2}$. Sudut penekanan $90^{\circ}, 75^{\circ}, 60^{\circ}, 45^{\circ}, 30^{\circ}$ dan kedalaman penekanan 4 $\mathrm{cm}, 8 \mathrm{~cm}, 12 \mathrm{~cm}, 16 \mathrm{~cm}$ dan $20 \mathrm{~cm}$. Dari hasil pengukuran diperoleh bahwa semakin besar ukuran plat maka gaya penekanan semakin besar namun tahanan penetrasi tanah semakin kecil. Sedangkan semakin dalam plat masuk ke tanah maka tahanan penetrasi tanah semakin besar. Semakin besar sudut penekanan tahanan penetrasi tanah semakin besar. Untuk ukuran plat, sudut tekan dan kedalaman penekanan plat yang sama pada kedalaman lumpur yang berbeda akan menghasilkan gaya penekanan dan tahanan penetrasi tanah yang berbeda.
\end{abstract}

\section{Pendahuluan}

Tanah terdiri dari partikel padatan dan rongga yang terisi oleh air dan atau udara. Jika tanah mendapat tekanan yang cukup besar maka volume tanahnya akan berubah. Perubahan ini dapat disebabkan oleh gaya-gaya luar dari sumber mekanis maupun sumber alam. Kondisi tanah dapat ditentukan dengan parameter-parameter tertentu seperti void ratio, porositas, berat isi tanah (bulk density), dan berat jenis isi menurut Mandang dan Nishimura [1].

Kadar air lahan sawah untuk padi menurut Hermawan et.al [2] biasanya sangat tinggi dan terkadang kendaraan dioperasikan pada permukaan yang jenuh dan berair sehingga lalu lintas di permukaan sangat sulit. Tanah yang sangat lunak ini salah satu sumber terbesar dari sulitnya mekanisasi pada budidaya padi di sawah.

Kekuatan tanah (soil strength) bervariasi secara sistematik menurut kadar air dan kerapatan tanah, selain dapat juga berubah karena tekstur tanah menurut Hettiaratchi et. al [3] . Salah satu permasalahan teknis yang banyak dijumpai dalam penerapan alat mekanis adalah rendahnya efisiensi akibat besarnya tahanan yang dialami oleh peralatan selama operasi. Menurut Rizaldi, dkk [4] bahwa roda besi bersirip merupakan pilihan yang terbaik untuk menghasilkan traksi di lahan sawah. Sirip-sirip roda menekan tanah pada sudut dan kedalaman tertentu untuk mendapatkan gaya reaksi yang sama dari tanah sehingga roda bisa bergerak.Tujuan penelitian ini adalah untuk menentukan besarnya gaya reaksi tanah pada lahan sawah melalui penekanan plat dengan berbagai ukuran dan sudut penekanan. 


\section{Bahan dan Metode}

\subsection{Lokasi Penelitian}

Pengukuran gaya reaksi tanah terhadap plat dilakukan pada lahan sawah di Desa Lubuk Bayas Kecamatan Perbaungan Kabupaten Serdang Bedagai. Lokasi yang dipilih adalah lahan sawah habis panen dan siap untuk dilakukan pengolahan tanah kembali.

\subsection{Metode}

Pengukuran nilai tahanan penetrasi tanah dilakukan pada bulan Agustus 2017 dengan menggunakan proving ring penetrometer. Pada ujung penetrometer dipasang plat besi. Plat besi yang digunakan memiliki tebal $4 \mathrm{~mm}$ dengan empat ukuran berbeda yaitu $5 \mathrm{~cm}$ x $5 \mathrm{~cm}, 10 \mathrm{~cm}$ x $5 \mathrm{~cm}, 15 \mathrm{~cm}$ x $5 \mathrm{~cm}$ dan $20 \mathrm{~cm}$ x $5 \mathrm{~cm}$. Sudut tekanan $(\alpha)$ dapat diatur dengan bantuan penyangga yang dipasang pada penetrometer. Sudut tekanan yang digunakan mulai dari $15^{\circ}$, $30^{\circ}, 45^{\circ}, 60^{\circ}, 75^{\circ}$ dan $90^{\circ}$ dengan kedalaman plat masuk ke tanah $4 \mathrm{~cm}, 8 \mathrm{~cm}, 12 \mathrm{~cm}, 16 \mathrm{~cm}$ dan $20 \mathrm{~cm}$. Pengukuran tanah dilakukan di sawah menurut Rizaldi , dkk [5].

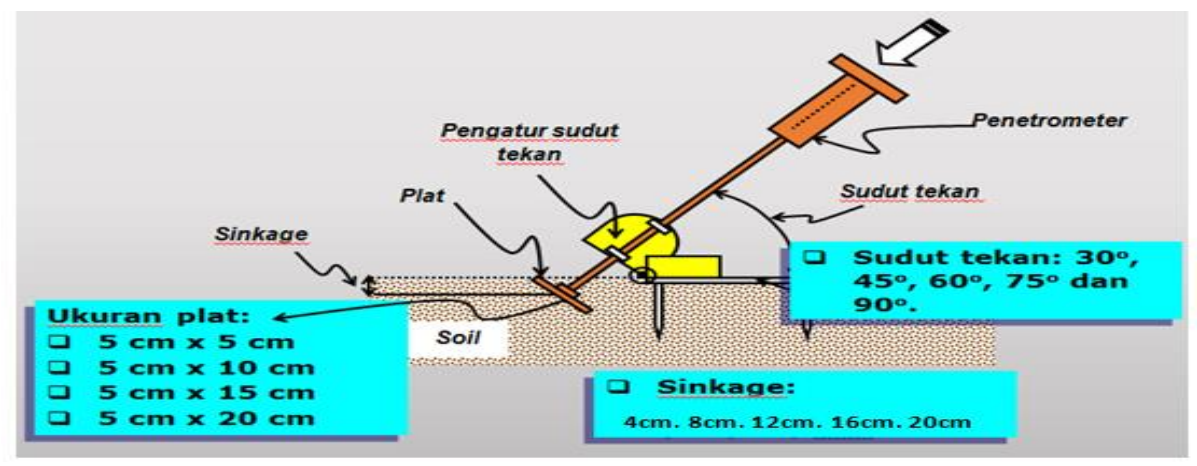

Gambar 1. Skema pengukuran gaya reaksi tanah terhadap plat

Gaya tekan yang dihasilkan pada penetrometer dicatat. Nilai tahanan penetrasi tanah terhadap penekanan plat dapat dihitung dengan persamaan :

$$
P=\frac{F}{A}
$$

Dimana $\mathrm{P}$ adalah tahanan penetrasi tanah $(\mathrm{Pa}), \mathrm{F}$ adalah gaya penekanan $(\mathrm{N})$ dan $\mathrm{A}$ adalah luas plat besi $\left(\mathrm{m}^{2}\right)$ Salokhe, et al [6].

\section{Hasil}

Penelitian dilakukan di Desa Lubuk Bayas Kecamatan Perbaungan Kabupaten Serdang Bedagai dengan tekstur tanah lempung berpasir (pasir 70\%, debu $17.33 \%$ dan liat $12.67 \%$ berdasarkan segitiga USDA), kadar air $49.17 \%$ dan bulk density $1.26 \mathrm{gr} / \mathrm{cm}^{3}$. Hasil pengukuran disajikan pada Tabel 1. 
Tabel 1. Data pengukuran tahanan penetrasi tanah terhadap penekanan plat

\begin{tabular}{|c|c|c|c|c|c|c|}
\hline \multirow{2}{*}{$\begin{array}{l}\text { Ukuran Plat } \\
\left(\mathrm{cm}^{2}\right)\end{array}$} & \multirow{2}{*}{$\begin{array}{l}\text { Sudut Tekan } \\
\left({ }^{\circ}\right)\end{array}$} & \multicolumn{5}{|c|}{$\begin{array}{l}\text { Daya Penekanan }(\mathrm{kPa}) \\
\text { Kedalaman Tekan }\end{array}$} \\
\hline & & 4 & 8 & 12 & 16 & 20 \\
\hline \multirow[t]{5}{*}{$5 \times 5$} & 90 & 83.71 & 154.34 & 211.90 & 274.68 & 329.62 \\
\hline & 75 & 77.17 & 146.50 & 207.97 & 243.29 & 290.38 \\
\hline & 60 & 68.02 & 130.80 & 168.73 & 204.05 & 282.53 \\
\hline & 45 & 57.55 & 115.10 & 162.19 & 201.43 & 236.75 \\
\hline & 30 & 30.08 & 39.24 & 62.78 & 83.71 & 107.26 \\
\hline \multirow[t]{5}{*}{$5 \times 10$} & 90 & 52.32 & 81.10 & 109.87 & 140.61 & 168.73 \\
\hline & 75 & 48.40 & 78.48 & 107.26 & 130.15 & 149.11 \\
\hline & 60 & 45.78 & 68.02 & 93.52 & 120.99 & 145.19 \\
\hline & 45 & 41.20 & 67.36 & 92.87 & 115.76 & 139.30 \\
\hline & 30 & 36.62 & 57.55 & 75.21 & 92.87 & 112.49 \\
\hline \multirow[t]{5}{*}{$5 \times 15$} & 90 & 41.42 & 65.40 & 86.33 & 99.41 & 118.16 \\
\hline & 75 & 39.68 & 61.48 & 83.28 & 96.79 & 110.74 \\
\hline & 60 & 38.37 & 57.99 & 76.74 & 93.74 & 107.69 \\
\hline & 45 & 35.75 & 54.94 & 75.43 & 85.02 & 100.28 \\
\hline & 30 & 29.65 & 46.22 & 61.48 & 73.25 & 92.43 \\
\hline \multirow[t]{5}{*}{$5 \times 20$} & 90 & 41.86 & 63.11 & 73.58 & 81.42 & 91.89 \\
\hline & 75 & 37.61 & 50.69 & 63.44 & 76.52 & 85.35 \\
\hline & 60 & 34.99 & 49.70 & 63.11 & 75.21 & 84.69 \\
\hline & 45 & 32.70 & 47.74 & 62.13 & 73.25 & 80.77 \\
\hline & 30 & 29.10 & 42.84 & 57.55 & 67.36 & 77.50 \\
\hline
\end{tabular}

Berdasarkan Tabel 1 data yang diperolah merupakan rata-rata dari 3 kali ulangan perlakuan. Hasil pengukuran menunjukkan adanya perbedaan tahanan penetrasi tanah akibat perubahan sudut tekan, ukuran plat dan kedalaman penekanan.

\subsection{Pengaruh kedalaman penekanan terhadap daya penekanan di setiap sudut tekan}

Semakin dalam plat masuk ke dalam tanah, gaya reaksi tanah terhadap plat juga semakin besar. Hubungan antara kedalaman penekanan terhadap daya penekanan disajikan pada Gambar 2.
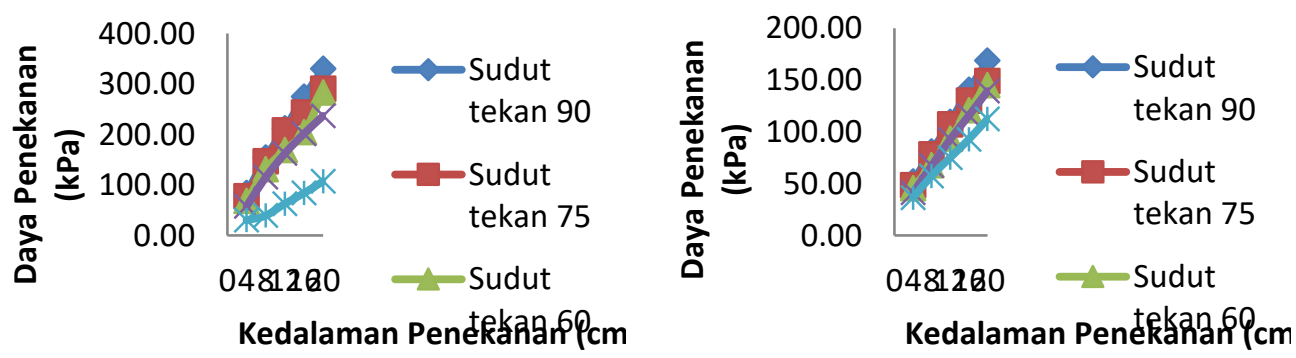

(a)

(b) 


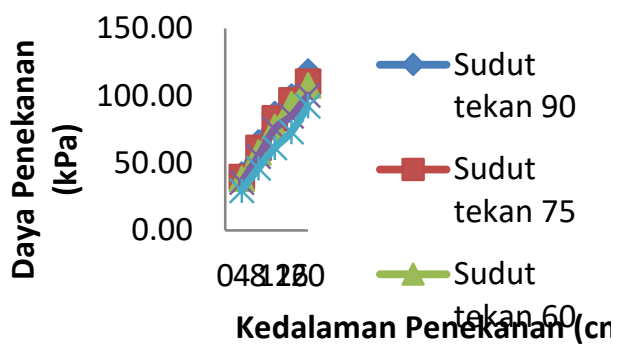

(c)

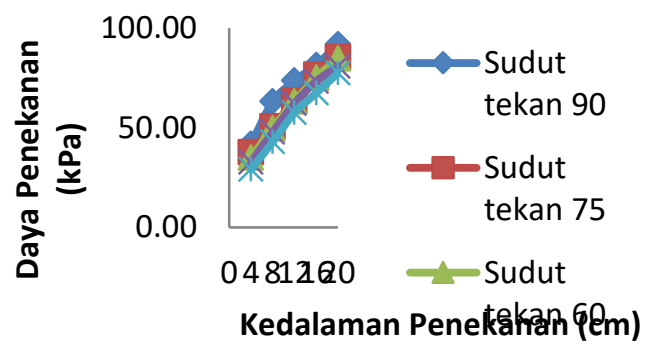

(d)

Gambar 2. Hubungan kedalaman penekanan plat terhadap daya penekanan disetiap sudut tekan pada ukuran plat (a) $5 \times 5 \mathrm{~cm} 2$, (b) $5 \times 10 \mathrm{~cm} 2$, (c) $5 \times 15 \mathrm{~cm} 2$, (d) $5 \times 20 \mathrm{~cm} 2$.

\subsection{Pengaruh ukuran plat terhadap daya penekanan di setiap sudut penekanan}

Ukuran plat sangat mempengaruhi daya penekanan pada tanah. Daya tekan yang diberikan ke tanah mendapatkan gaya reaksi yang besarnya sama oleh tanah. Gambar berikut menyajikan pengaruh ukuran plat terhadap daya penekanan di setiap sudut penekanan pada kedalaman tekan yang berbeda.

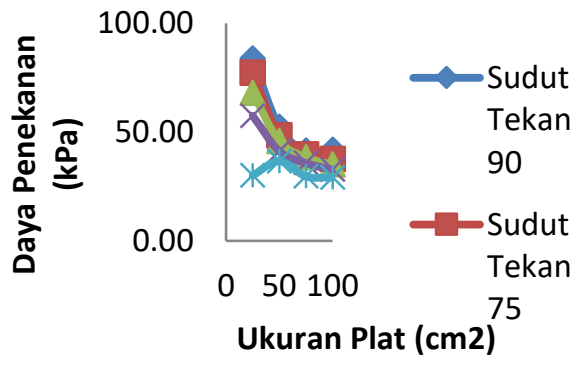

(a)

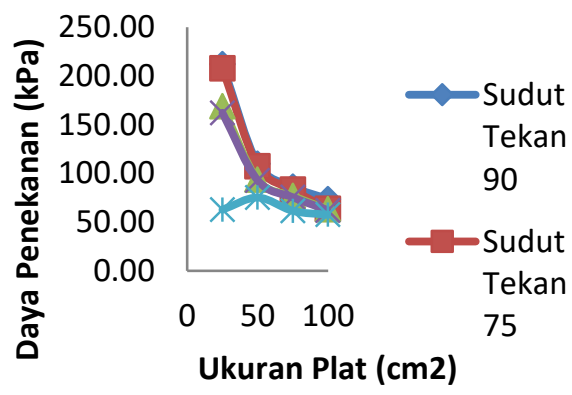

(c)

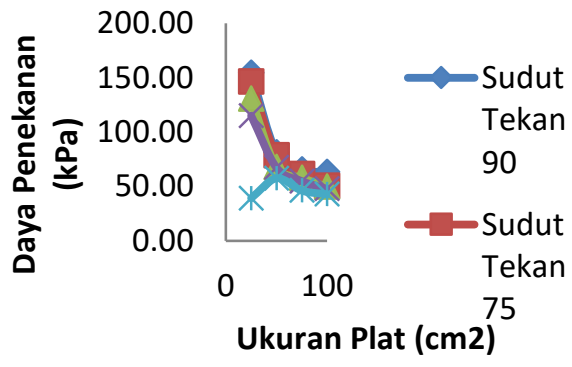

(b)



(d) 


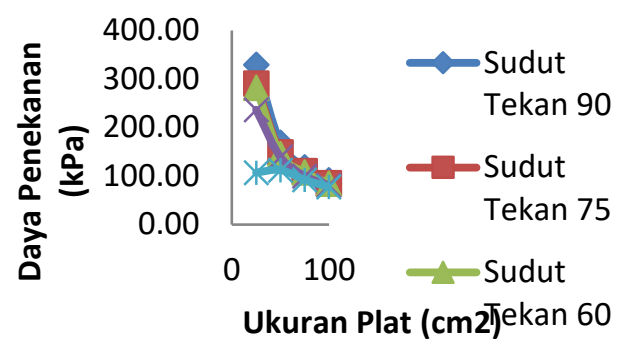

(e)

Gambar 3. Hubungan ukuran plat terhadap daya penekanan di setiap sudut tekan pada kedalaman (a) $4 \mathrm{~cm}$, (b) $8 \mathrm{~cm}$, (c) $12 \mathrm{~cm}$, (d) $16 \mathrm{~cm}$, (e) 20 $\mathrm{cm}$

\section{Pembahasan}

Gambar 1 di atas menjelaskan bahwa semakin dalam plat masuk ke dalam tanah maka semakin besar pula daya penekanan dan ini terjadi pada setiap ukuran plat. Hal ini disebabkan pada saat plat masuk semakin dalam ke tanah, maka semakin dekat pula plat menuju bagian lapisan keras tanah.

Gambar 2 menunjukkan bahwa semakin besar ukuran plat, gaya penekanan juga semakin besar. Namun demikian, keadaan sebaliknya terjadi pada daya penekanan. Semakin besar ukuran plat maka daya penekanan semakin kecil. Hal ini sesuai dengan persamaan $\mathrm{P}=\mathrm{F} / \mathrm{A}$ dimana gaya penekanan berbanding terbalik dengan luas plat.

\section{Kesimpulan dan Saran}

Bertambahnya ukuran plat berbanding lurus dengan meningkatnya gaya penekanan dan berbanding terbalik dengan tahanan penetrasi tanah. Bertambahnya kedalaman penekanan plat berbanding lurus dengan meningkatnya tahanan penetrasi tanah. Bertambahnya sudut tekan maka gaya penekanan dan tahanan penetrasi tanah semakin besar.

Data tahanan penetrasi tanah terhadap penekanan plat dapat digunakan untuk menentukan kemampuan roda beroperasi di sawah. Data tahanan penetrasi tanah terhadap penekanan plat dapat digunakan untuk mendisain roda besi bersirip optimum.

\section{Ucapan Terima Kasih}

Terimakasih kepada Direktorat Riset dan Pengabdian Masyarakat Direktorat Jendral Penguatan Riset dan Pengembangan Kementerian Riset, Teknologi, dan Pendidikan Tinggi atas Dana Penelitian yang diberikan sesuai dengan Kontrak Penelitian Nomor: 003/SP2H/LT/DRPM/IV/2017 tanggal 20 April 2017.

\section{Referensi}

[1] Mandang T dan Nishimura I 1991. Hubungan Tanah dan Alat Pertanian. JICA-DGHE/IPB PROJECT: JTA-9a(132) . Proyek Peningkatan Perguruan Tinggi. Bogor (ID): Intitut Pertanian Bogor.

[2] Hermawan W, Yamazaki M, Oida A 1998. Experimental Analysis of Soil Reaction on A Lug of A Movable Lug Wheel. Journal of Terramechanics.35(2):119-135.

[3] Hettiaratchi D R P, Witney B D and Reece R 1966. The calculation of passiv pressure in two-dimensional soil failure. Journal of Agricultural Engineering Research.11(2): 89-107.

[4] Rizaldi T, Hermawan W, Mandang T, Pertiwi S 2014. Tractive Performance Testing of Lug Wheel in a Soil Bin. International Journal of Scientific \& Engineering Research. 5(7):521-525 
[5] Rizaldi T, Hermawan W, Mandang T, Pertiwi S. 2014. Penentuan parameter disain roda besi bersirip melalui pengukuran tahanan penetrasi tanah di sawah. Jurnal AGRITECH. 34(4): 473-480.

[6] Salokhe V M, Manzoor S, Gee-Clough D 1990. Pull and Lift Forces Acting on Single Cage Wheel Lugs. Journal of Terramechanics. 27(1):25-39. 